\title{
New Sol-Gel Synthetic Route to Transition and Main-Group Metal Oxide Aerogels using Inorganic Salt Precursors
}

A.E. Gash, T.M. Tillotson, J.H. Satcher, L.W. Hrubesh, R.L Simpson

This article was submitted to Sixth International Symposium on Aerogels, Albuquerque, NM, October 8-11, 2000

September 12, 2000 


\section{DISCLAIMER}

This document was prepared as an account of work sponsored by an agency of the United States Government. Neither the United States Government nor the University of California nor any of their employees, makes any warranty, express or implied, or assumes any legal liability or responsibility for the accuracy, completeness, or usefulness of any information, apparatus, product, or process disclosed, or represents that its use would not infringe privately owned rights. Reference herein to any specific commercial product, process, or service by trade name, trademark, manufacturer, or otherwise, does not necessarily constitute or imply its endorsement, recommendation, or favoring by the United States Government or the University of California. The views and opinions of authors expressed herein do not necessarily state or reflect those of the United States Government or the University of California, and shall not be used for advertising or product endorsement purposes.

This is a preprint of a paper intended for publication in a journal or proceedings. Since changes may be made before publication, this preprint is made available with the understanding that it will not be cited or reproduced without the permission of the author.

This work was performed under the auspices of the United States Department of Energy by the University of California, Lawrence Livermore National Laboratory under contract No. W-7405-Eng-48.

This report has been reproduced directly from the best available copy.

Available electronically at http://www.doc.gov/bridge

Available for a processing fee to U.S. Department of Energy

And its contractors in paper from

U.S. Department of Energy

Office of Scientific and Technical Information

P.O. Box 62

Oak Ridge, TN 37831-0062

Telephone: (865) 576-8401

Facsimile: (865) 576-5728

E-mail: reports@adonis.osti.gov

Available for the sale to the public from

U.S. Department of Commerce

National Technical Information Service

5285 Port Royal Road

Springfield, VA 22161

Telephone: (800) 553-6847

Facsimile: (703) 605-6900

E-mail: orders@ntis.fedworld.gov

Online ordering: http://www.ntis.gov/ordering.htm

OR

Lawrence Livermore National Laboratory

Technical Information Department's Digital Library

http://www.llnl.gov/tid/Library.html 


\title{
New Sol-Gel Synthetic Route to Transition and Main-Group Metal Oxide Aerogels Using Inorganic Salt Precursors
}

\author{
Alexander E. Gash, ${ }^{*}, \uparrow$ Thomas M. Tillotson, ${ }^{\dagger}$ Joe H. Satcher, Jr., $†$ \\ Lawrence W. Hrubesh, ${ }^{\dagger}$ and Randall L. Simpson \\ Chemistry and Material Science Directoratet \\ and Energetic Materials Center, $\neq$ \\ Lawrence Livermore National Laboratory, Livermore, CA 94550
}

\begin{abstract}
We have developed a new sol-gel route to synthesize several transition and main-group metal oxide aerogels. The approach is straightforward, inexpensive, versatile, and it produces monolithic microporous materials with high surface areas. Specifically, we report the use of epoxides as gelation agents for the sol-gel synthesis of chromia aerogels and xerogels from simple Cr(III) inorganic salts. The dependence of both gel formation and its rate was studied by varying the solvent used, the $\mathrm{Cr}(\mathrm{III})$ precursor salt, the epoxide/Cr(III) ratio, as well as the type of epoxide employed. All of these variables were shown to affect the rate of gel formation and provide a convenient control of this parameter. Dried chromia aerogels were characterized by high-resolution transmission electron microscopy (HRTEM) and nitrogen adsorption/desorption analyses, results of which will be presented. Our studies have shown that rigid monolithic gels can be prepared from many different metal ions salts, provided the formal oxidation state of the metal ion is greater than or equal to +3 . Conversely, when di-valent transition metal salts are used precipitated solids are the products.
\end{abstract}

\section{Introduction}


Sol-gel chemistry is an attractive alternative to other synthetic methods for many reasons. The method is low temperature, low cost, and can generally be done under room conditions with general lab equipment, all of which make processing convenient and inexpensive. Historically, the sol-gel method has employed the use of metal alkoxide precursors that readily undergo catalyzed hydrolysis and condensation to form a sol of metal oxide particles with nanoscale dimensions (1-100 nm).[1] This synthetic route has proven to be an efficient, easy, and successful approach to the production of many different materials.[1,2] However, some metal alkoxides are expensive and still others are sensitive to moisture, heat, and light making long term storage difficult. Further still, some metal alkoxides are not commercially available or are difficult to obtain, thus precluding detailed studies on the preparation, characterization, and potential applications of their resulting metal oxide aerogels.

With the particular exceptions of titanium and zirconium, alkoxide-transition metal precursors are not readily available. In the absence of the alkoxides researchers have used more traditional approaches for the successful sol-gel preparation of transition metal oxide. This approach typically involves aqueous precipitation of the metal ion with base, extensive washing and solvent exchange of the products followed by atmospheric or supercritical drying.[2] For example, vibrant chromia (the generic term for hydrated chromic oxide of unknown hydration) gels have been prepared by such methods by several researchers.[3-5]

Although the preparation of aerogels and xerogels of chromia has been previously accomplished, there are relatively few reports in the literature describing it.[6-8] The main synthetic route employed relies on high temperature $\left(\sim 300^{\circ} \mathrm{C}\right)$ supercritical solvent processing. Currently, the primary interest in high surface area chromia-based materials are in their utility as catalysts.[9] High surface area chromia-based materials are catalysts for halogenations of hydrocarbons (especially fluorinations),[10] the dehydration of alcohols, the dehydrogenation of alkanes and olefins, and isomerization reactions. 
We have previously used propylene oxide as a gelation promoter in the sol-gel synthesis of lanthanide and lanthanide-silicate gels using hydrated lanthanide nitrate salts.[11] We have also reported on the use of this synthetic route to make porous $\mathrm{Fe}_{2} \mathrm{O}_{3}$ solids.[12] Itoh et al. has reported the use of propylene oxide in the sol-gel preparation of silicate-aluminate gels using hydrated aluminum chloride as the Al source.[13] Here we report the use of epoxides as gelation agents for the sol-gel synthesis of chromia aerogels and xerogels from simple Cr(III) inorganic salts. This method is safe, low-cost, lowtemperature, versatile, and requires relatively few steps to produce porous metal oxide monoliths. In addition, this general method can be used for the preparation of other metal oxide aerogels.

\section{Experimental}

Chromium(III) nitrate nonahydrate, $\quad \mathrm{Cr}\left(\mathrm{NO}_{3}\right)_{3} \cdot 9 \mathrm{H}_{2} \mathrm{O}$ (Aldrich), and chromium(III) chloride hexahydrate, $\mathrm{CrCl}_{3} \cdot 6 \mathrm{H}_{2} \mathrm{O}$ (Aldrich), and propylene oxide (99\%; Aldrich) were used as received. All solvents used were reagent grade or better and the $\mathrm{H}_{2} \mathrm{O}$ used was distilled. All syntheses were performed under room conditions. In a typical experiment, $0.65 \mathrm{~g}$ of $\mathrm{Cr}\left(\mathrm{NO}_{3}\right)_{3} \cdot 9 \mathrm{H}_{2} \mathrm{O}(1.6 \mathrm{mmol})$ was dissolved in $2.5 \mathrm{ml}$ of 200 proof ethanol to give a clear dark blue solution that remained unchanged upon storage, under room conditions, for several months. If instead, a $1.0 \mathrm{~g}$ portion of propylene oxide (17 mmol) was added to the solution a dark blue transparent gel formed within a few hours.

\subsection{Gel processing conditions}

Aerogel samples were processed in Polaron ${ }^{\mathrm{TM}}$ supercritical point drier. The solvent liquid in the wet gel pores was exchanged for $\mathrm{CO}_{2}(l)$ for several days. Then the temperature of the vessel was ramped up to $\sim 45^{\circ} \mathrm{C}$, while maintaining a pressure of $\sim 100$ 
bars. The vessel was then depressurized at a rate of about 7 bars per hour. Xerogel samples were processed by allowing them to dry under room conditions.

\subsection{Physical characterization}

Surface area and pore volume and size analyses were performed by BET (Brunauer-Emmett-Teller) and BJH (Barrett-Joyner-Halenda) methods using an ASAP 2000 Surface area Analyzer (Micromeritics Instrument Corporation).[14] Samples of approximately $0.1-0.2 \mathrm{~g}$ were heated to $200^{\circ} \mathrm{C}$ under vacuum $\left(10^{-5}\right.$ Torr $)$ for at least 24 hours to remove all adsorbed species. Nitrogen adsorption data was taken at five relative pressures from 0.05 to 0.20 at $77 \mathrm{~K}$, to calculate the surface area by BET theory. The high resolution transmission electron microscopy (HRTEM) was performed on a Philips CM300FEG operating at $300 \mathrm{Kev}$ using zero loss energy filtering with a Gatan energy Imaging Filter (GIF) to remove inelastic scattering. The images where taken under BF (bright field) conditions and slightly defocused to increase contrast. The images were also recorded on a $2 \mathrm{~K} \times 2 \mathrm{~K}$ CCD camera attached to the GIF.

\section{Results}

A summary of the various synthetic conditions used to prepare dark blue chromia gels is shown in Table 1. This synopsis indicates that several synthetic combinations resulted in the formation of strong dark blue monolithic gels. An advantage of this method that is clear from inspection of Table 1 is the number of solvents that are compatible with this method. Successful syntheses were achieved in most of the polar protic and polar aprotic solvents employed. In addition, the syntheses can be performed with either the nitrate or chloride $\mathrm{Cr}$ (III) salt. Qualitatively it appears that gelation is faster when the chloride precursor is used. The gel times for chromia were dependent on the identity of the solvent. For example, the gel time for the synthesis in methanol was 
14 hours whereas that for $t$-butanol was 1.3 hours. We attribute this to differences in solubility of the chromia sol particles in each solvent

One synthetic parameter that was extensively investigated was the ratio of propylene oxide to $\mathrm{Cr}(\mathrm{III})$ used . Several experiments were run where that ratio was varied from 3-25. The rate of gel formation was observed to increase with this ratio. These experiments also indicated that there is a critical ratio below which no gel formation is observed even after several months. That minimum value is 7 for the synthetic conditions described here $\left([\mathrm{Cr}]=0.35 \mathrm{M} ; \mathrm{H}_{2} \mathrm{O} / \mathrm{Cr}=9\right.$; solvent = ethanol). However, it is not necessary that all 7 equivalents of propylene oxide be delivered at one time.

Dark blue gels were formed using a delayed-addition synthetic method. For example, four equivalents of propylene oxide were added to an ethanolic solution containing dissolved $\mathrm{Cr}(\mathrm{III})$. On standing for several days there was no observed gel formation. Subsequent addition of four more equivalents of propylene oxide resulted in the formation of a gel within several hours. According to our previous experiments four equivalents of propylene oxide are not sufficient to induce the gelation of the solution. Therefore, neither aliquot of propylene oxide was large enough to cause gelation but the sum total of the two was.

Propylene oxide was shown to be an effective gelation agent for the formation of chromia gels. Since there are a variety of commercially available epoxides we decided to see if some of them were also effective gelation agents. The results of these experiments (not shown in this report) indicate that other epoxides can be used to prepare gels. In fact, every epoxide used induced gelation. Other epoxides employed were 1,2epoxybutane, 1,2-epoxypentane, 2,3-epoxy(propyl)benzene, trimethylene oxide, glycidol, epichlorohydrin, and epibromohydrin. The rate of gel formation in these experiments depended on the identity and number of substituents on the epoxide ring. This was also observed in the $\mathrm{Fe}_{2} \mathrm{O}_{3}$ report and provides a convenient synthetic parameter that can be varied by the chemist. 
Some of the gels from Table 1 were processed to aerogels and xerogels, respectively. A photo of a processed and dried chromia aerogel is shown in Figure 1. The aerogel densities were highly reproducible and were found to depend on the solvent used for synthesis. Aerogels with densities from $80 \mathrm{mg} / \mathrm{ml}$ to $600 \mathrm{mg} / \mathrm{ml}$ and xerogels with densities $1100-1300 \mathrm{mg} / \mathrm{ml}$ were readily prepared. These gels are very robust and provide nice monoliths. This feature has allowed us to determine some of their mechanical properties using acoustical methods. The integrity of the aerogel monoliths also allows them to be cast and used in complex geometric shapes.

We utilized high-resolution transmission electron microscopy (HRTEM) to examine the nanostructure of the chromia aerogels. Figure 2 contains a HRTEM micrograph of a chromia aerogel. Qualitatively, the material appears to be a collection of clusters of particles that contain cavities of mesoporous dimensions. The micrograph in Figure 2 is sufficiently high magnification as to provide a fine representation of the size, shape, and connectivity of the particles that make up the aerogel. It appears that the gel is made up of relatively uniform spherical particles with most having diameters in the $\sim 5$ $\mathrm{nm}$ range. It is important to point out here that it appears that the gel is made up entirely of these uniformly sized particles. Microscopy results from a report by Saraswat et al. on a chromium oxide hydrate gel, prepared by precipitation with hydroxide, showed the presence of at least three different phases, two of which were crystalline.[5] The gel shown in Figure 2 appeared amorphous, as is did not diffract electrons under the electron microscope.

Table 2 summarizes the surface areas, pore volumes, and average pore sizes for some chromia aerogels. In general, all of the materials listed in Table 2 have high surface areas and pore diameters whose dimensions are in the mesoporic $(2-20 \mathrm{~nm})$ region. The surface areas of the chromia aerogels reported here are comparable to those reported by Skapin et al.(300-550 $\left.\mathrm{m}^{2} / \mathrm{g}\right)$ and Armor et al.(500-700 $\left.\mathrm{m}^{2} / \mathrm{g}\right) \cdot[7,8]$ The surface areas of our materials are significantly higher than those reported for chromium(III) oxide gels 
prepared by precipitation with base and those for commercial chromia catalysts. $[7,15]$ The adsorption/desorption isotherms for the aerogel materials displayed the classic shape of a Type IV isotherm, that is indicative of a mesoporous material.[14] Finally, all of the chromia materials had narrow pore size distributions.

With our demonstrated successes in the syntheses of chromia and $\mathrm{Fe}_{2} \mathrm{O}_{3}$ porous materials using the epoxide addition method it was a logical progression to apply it to the preparation of other metal oxide aerogels. We attempted to synthesize aerogels of several different metal oxides using the epoxide addition method, the results of which are summarized in Table 3. We were able to prepare monolithic particular aerogels of several different metal oxides. However not all of our attempts were successful. In particular, we were unable to achieve monolithic gel formation in any of the attempted syntheses with $\mathrm{M}^{2+}$ ions $\left(\mathrm{M}=\mathrm{Ni}^{2+}, \mathrm{Co}^{2+}, \mathrm{Zn}^{2+}, \mathrm{Mn}^{2+}\right.$, and $\left.\mathrm{Cu}^{2+}\right)$. In all of those cases precipitates were obtained.

\section{Discussion}

As we have previously shown with $\mathrm{Fe}_{2} \mathrm{O}_{3}$ gels water is also a crucial ingredient in the preparation of chromia gels. Water was present in all of the successful syntheses shown in Table 1. We believe that the presence of a significant amount of water is necessary for the formation of the $\left[\mathrm{Cr}\left(\mathrm{H}_{2} \mathrm{O}\right)_{6}\right]^{3+}$ species that is the solution phase precursor to these materials.[16] The water molecules on the $\left[\mathrm{Cr}\left(\mathrm{H}_{2} \mathrm{O}\right)_{6}\right]^{3+}$ species are relatively acidic due to charge transfer from them to the $\mathrm{Cr}^{3+}$ metal center.[2] We postulate that the species is acidic enough to donate protons to the added propylene oxide (a well known proton scavenger used in many organic reactions).[17] The protonated propylene oxide then undergoes and irreversible ring-opening reaction with the nucleophilic anion of the $\mathrm{Cr}^{3+}$ salt (either chloride or nitrate ion in this report). The net effect is to raise the $\mathrm{pH}$ of the solution slowly and homogeneously that results in the 
formation of aquo-hydroxy species of $\mathrm{Cr}^{3+}\left(\left[\mathrm{Cr}(\mathrm{OH})_{x}\left(\mathrm{H}_{2} \mathrm{O}\right)_{6-\mathrm{x}}\right]^{+3-\mathrm{x}}\right) \cdot[18]$ These metal ion species are susceptible to the condensation reactions of olation and oxolation to yield oligomeric species.[2] The oligomers can undergo further condensation to form a sol of chromia particles that further condense to form a gel. We have helped confirm this by monitoring the $\mathrm{pH}$ rise in aqueous syntheses of chromia gels (from $\sim 1$ before epoxide addition to $\sim 6$ just before gelation). In addition, we have validated this general gel mechanism using $\mathrm{pH}$ and $\mathrm{NMR}$ studies on the formation of $\mathrm{Fe}_{2} \mathrm{O}_{3}$ gels using this same method. It is our contention that the general mechanism of gel formation is the same for both metal ions.

The gel times for the chromia gels were significantly longer than those observed for $\mathrm{Fe}_{2} \mathrm{O}_{3}$ gel formation under identical conditions. Typically the $\mathrm{Fe}_{2} \mathrm{O}_{3}$ gels took only several minutes to form. We believe that the significantly longer gel times for the chromia can be attributed to the inert character of the $\mathrm{Cr}^{3+}\left(d^{3}\right)$ ion towards substitution. It is well known that $d^{3}$ electronic configuration is kinetically inert due to its high crystal field stabilization in the octahedral field. On the contrary, $\mathrm{Fe}^{3+}\left(d^{5}\right)$ ion is labile and is well known to undergo rapid hydrolysis and condensation.[16]

The HRTEM results indicate that the chromia gels are particulate gels made up of particles with diameters on the order of $\sim 5 \mathrm{~nm}$. The particles that make up the gel appear to be uniform and not a mixture of crystalline phases as has been reported by Saraswat et al. for the synthesis of chromia gel by precipitation from aqueous solution with base.[5] Although straightforward, the base addition method is somewhat time consuming as the gel must be washed and the water exchanged for a solvent that is miscible with $\mathrm{CO}_{2}(l)$. On a microstructural level, the particle size and the chromia aerogel's appearance, as an agglomeration of spherical particles, are similar to both the particle size and morphology of base-catalyzed silica aerogels rather than acid-catalyzed ones.

According to nitrogen adsorption/desorption analyses the chromia aerogels produced by this method are mesoporous solids with moderately high surface areas. It is 
interesting to note that base-catalyzed silica aerogels have similar pore diameters and surface areas. These results, along with those from HRTEM, simply illustrate a parallel between the gel morphology and pore structure of the two different materials. The surface area measurements of our materials are comparable to those reported for chromia aerogels made by Armor et al. and Skapin et al.[6-8] However, their method involved the addition of an aqueous suspension of $\mathrm{CrO}_{3}$ to methanol followed by supercritical processing to chemically reduce the $\mathrm{Cr}(\mathrm{IV})$ to $\mathrm{Cr}(\mathrm{III})$ and form chromia. Chromium trioxide is a powerful reducing agent and great care must be taken to avoid a violent reaction with alcohols. The high temperature and pressures of this process require the use of expensive and sophisticated processing equipment. This fact coupled with the dangerous nature of the precursor solutions, that require extreme safety precautions, likely precludes the widespread application of this method. Therefore, we believe that the favorable nature of the starting materials, along with the one step synthetic approach, as well as relatively benign processing conditions make the epoxide addition procedure an important and new method for the preparation of chromia aerogels.

With the work presented here and elsewhere we have demonstrated that the epoxide addition method is applicable to the synthesis of monolithic aerogels of several transition and main group metal oxides. As stated previously, this method does not produce monolithic metal oxide gels from aqueous metal ions that have a formal charge of less than +3 . The reasons for this observation are not clearly understood. Generally the acidities of $\left[\mathrm{M}\left(\mathrm{H}_{2} \mathrm{O}\right)_{\mathrm{x}}\right]^{2+}$ complexes are much lower than those for aquo complexes where $\mathrm{M}^{\mathrm{n}}(\mathrm{n}=2,3,4,5,6)$.[19] Clearly this would slow down the protonation of the added epoxide and subsequent $\mathrm{pH}$ rise. The slow rate of this process may allow alternative side reactions to occur to a significant degree, which may cause precipitation to take place. At this time, the observations cannot be adequately explained. We are in the process of performing experiments to more clearly understand what is happening; the results of which will be reported elsewhere. 


\section{Conclusions}

A new safe and straightforward sol-gel method for the production of metal oxide aerogels was investigated. Implementation of this method allowed the preparation of monolithic chromia aerogels made up of uniform amorphous particles with $\sim 5 \mathrm{~nm}$ diameters and high surface areas $\left(400-500 \mathrm{~m}^{2} / \mathrm{g}\right)$. As discussed, the advantages of method are that it is relatively easy to perform, utilizes inexpensive precursors and processing conditions, and is safe. In addition, this method provides the chemist with a wide variety of conditions (i.e., solvent, precursor salt, type of epoxide) to obtain these materials. Finally, preliminary synthetic studies have shown that this general method can be used to prepare monolithic aerogels of other transition and main group metal oxides, as long as the formal oxidation state of the precursor metal ion is $\geq+3$.

\section{Acknowledgements}

This work was performed under the auspices of the U.S. Department of Energy by University of California Lawrence Livermore National Laboratory under contract No. W7405-Eng-48. Special thanks to Mr. Mark Wall for TEM analyses, and Mrs. Suzanne Hulsey for nitrogen adsorption/desorption analyses.

\section{References}

1) Brinker, C. J.; Scherer, G. W. Sol-Gel Science; Academic Press, Inc.: Boston, 1990.

2) Livage, J.; Henry, M.; Sanchez, C. Prog. Solid St. Chem. 1988, 18, 259.

3) Ratnasamy, P.; Leonard, A. J. J. Phys. Chem. 1972, 76, 1838.

4) Singh, K. K.; Sarode, P. R.; Ganguly, P. J. Chem. Soc. Dalton Trans. 1983, 1895.

5) Saraswat, I. P.; Vajpei, A. C. J. Mater. Sci. Lett. 1984, 3, 515.

6) Armor, J. N.; Carlson, E. J. Appl. Catal. 1985, 19, 327. 
7) Armor, J. N.; Carlson, E. J.; Conner, W. C., Jr. Reactivity of Solids 1987, 3, 155.

8) Skapin, T.; Kemnitz, E. J. Non-Cryst. Solids 1998, 225, 163.

9) Burwell, R. L., Jr.;; Haller, G. L.; Taylor, K. C.; Read, J. F. Chemisorptive and Catalytic Behavior of Chromia; Eley, D. D., Pines, H. and Weisz, P. B., Ed.; Academic Press: New York, 1969; Vol. 20.

10) Kemnitz, E.; Menz, D. H. Prog. Solid St. Chem. 1998, 26, 97.

11) Tillotson, T. M.; Sunderland, W. E.; Thomas, I. M.; Hrubesh, L. W. H. Sol-Gel Sci. Technol. 1994, 1, 241-249.

12) Gash, A. E.; Tillotson, T. M.; Satcher, J. H., Jr.; Poco, J. F.; Hrubesh, L. W.; Simpson, R. L. submitted to Chem. Mater. 2000, .

13) Itoh, H.; Tabata, T.; Kokitsu, M.; Okazaki, N.; Imizu, Y.; Tada, A. J. Ceram. Soc. Jpn. 1993, 101, 1081-1083.

14) Gregg, S. J.; Sing, K. S. W. Adsorption, Surface Area, and Porosity; 2nd ed.; Academic Press: London, 1982.

15) Padilla, A. M.; Corella, J.; Toledo, J. M. Appl. Catal. B 1999, 22, 107.

16) Cotton, F. A.; Wilkinson, G. Advanced Inorganic Chemistry; 5th ed.; John Wiley and Sons: New York, 1988.

17) Dobinson, B.; Hofmann, W.; Stark, B. P. The Determination of Epoxides; Permagon Press: Oxford, 1969.

18) Rai, D.; Sass, B. M.; Moore, D. A. Inorg. Chem. 1987, 26, 345.

19) Baes, C. F.; Mesmer, R. E., Jr. The Hydrolysis of Cations; John Wiley and Sons: New York, 1976. 


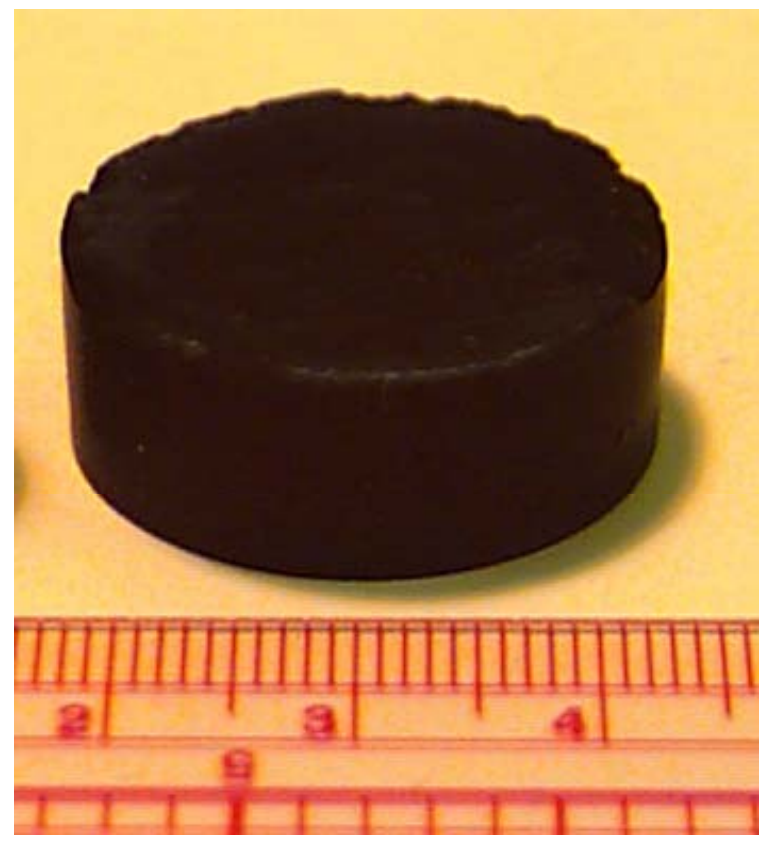

Figure 1. Photo of chromia aerogel monolith $(\rho=280 \mathrm{mg} / \mathrm{ml})$. The scale of the ruler in the photo is in $\mathrm{cm}$. 


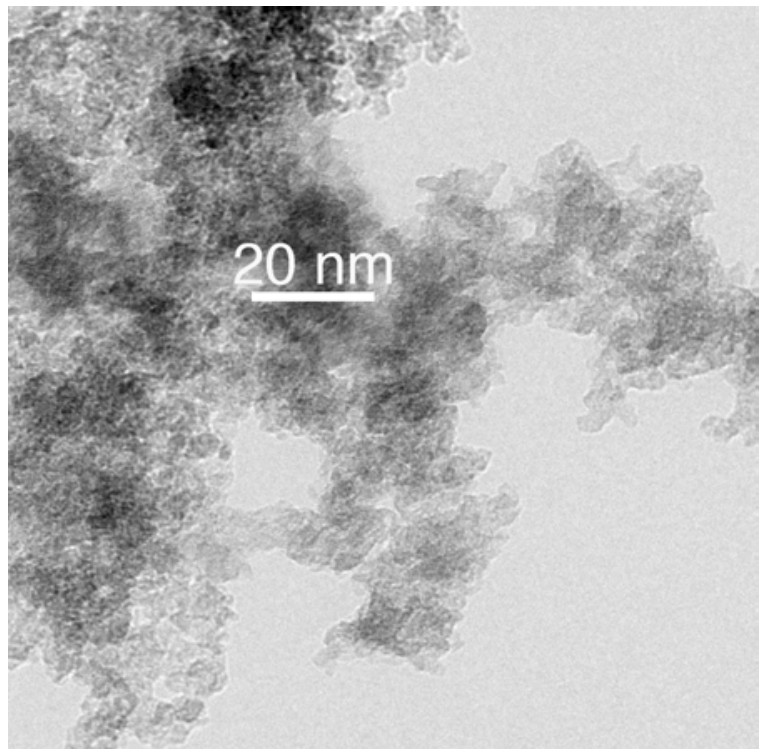

Figure 2. A high-resolution transmission electron micrograph of a chromia aerogel. 
Table 1. Summary of synthetic conditions for the synthesis of chromia gels $([\mathrm{Cr}]=0.35$ $\mathrm{M}$; propylene oxide $/ \mathrm{Fe}=11)(\mathrm{ppt} .=$ precipitation of dense solid $)$.

\begin{tabular}{|c|c|c|}
\hline $\begin{array}{l}\text { Precursor } \\
\text { Salt }\end{array}$ & solvent & $\begin{array}{c}t_{\text {gel }} \\
\text { (hours) }\end{array}$ \\
\hline $\mathrm{Cr}\left(\mathrm{NO}_{3}\right)_{3} \cdot 9 \mathrm{H}_{2} \mathrm{O}$ & methanol & 14 \\
\hline $\mathrm{Cr}\left(\mathrm{NO}_{3}\right)_{3} \cdot 9 \mathrm{H}_{2} \mathrm{O}$ & ethanol & 3.1 \\
\hline $\mathrm{Cr}\left(\mathrm{NO}_{3}\right)_{3} \cdot 9 \mathrm{H}_{2} \mathrm{O}$ & 1-propanol & 2.6 \\
\hline $\mathrm{Cr}\left(\mathrm{NO}_{3}\right)_{3} \cdot 9 \mathrm{H}_{2} \mathrm{O}$ & $t$-butanol & 1.3 \\
\hline $\mathrm{Cr}\left(\mathrm{NO}_{3}\right)_{3} \cdot 9 \mathrm{H}_{2} \mathrm{O}$ & 2-ethoxy ethanol & 2 \\
\hline $\mathrm{Cr}\left(\mathrm{NO}_{3}\right)_{3} \cdot 9 \mathrm{H}_{2} \mathrm{O}$ & DMF & 20 \\
\hline $\mathrm{Cr}\left(\mathrm{NO}_{3}\right)_{3} \cdot 9 \mathrm{H}_{2} \mathrm{O}$ & formamide & no gel \\
\hline $\mathrm{Cr}\left(\mathrm{NO}_{3}\right)_{3} \cdot 9 \mathrm{H}_{2} \mathrm{O}$ & DMSO & 72 \\
\hline $\mathrm{Cr}\left(\mathrm{NO}_{3}\right)_{3} \cdot 9 \mathrm{H}_{2} \mathrm{O}$ & ethylene glycol & $\sim 240$ \\
\hline $\mathrm{Cr}\left(\mathrm{NO}_{3}\right)_{3} \cdot 9 \mathrm{H}_{2} \mathrm{O}$ & water & no gel \\
\hline $\mathrm{Cr}\left(\mathrm{NO}_{3}\right)_{3} \cdot 9 \mathrm{H}_{2} \mathrm{O}$ & THF & ppt. \\
\hline $\mathrm{CrCl}_{3} \cdot 6 \mathrm{H}_{2} \mathrm{O}$ & water & $<2$ \\
\hline $\mathrm{CrCl}_{3} \cdot 6 \mathrm{H}_{2} \mathrm{O}$ & ethanol & 0.2 \\
\hline
\end{tabular}


Table 2. Summary of nitrogen adsorption/desorption analyses for some chromia aerogels.

\begin{tabular}{lcccc}
\hline $\begin{array}{l}\text { Precursor } \\
\text { Salt }\end{array}$ & solvent & $\begin{array}{c}\text { Surface } \\
\text { Area } \\
\left(\mathrm{m}^{2} / \mathrm{g}\right)\end{array}$ & $\begin{array}{c}\text { Pore } \\
\text { Vol. } \\
(\mathrm{ml} / \mathrm{g})\end{array}$ & $\begin{array}{l}\text { Ave. } \\
\text { Pore } \\
\text { Dia.(nm) }\end{array}$ \\
\hline $\mathrm{Cr}^{2}\left(\mathrm{NO}_{3}\right)_{3} \cdot 9 \mathrm{H}_{2} \mathrm{O}$ & $\mathrm{EtOH}$ & 490 & 1.64 & 11 \\
$\mathrm{CrCl}_{3} \cdot 6 \mathrm{H}_{2} \mathrm{O}$ & $\mathrm{EtOH}$ & 420 & 2.20 & 18 \\
$\mathrm{Cr}(\mathrm{Cl})_{3} \cdot 6 \mathrm{H}_{2} \mathrm{O}$ & $\mathrm{H}_{2} \mathrm{O}$ & 520 & 1.90 & 11 \\
& & & & \\
\hline
\end{tabular}


Table 3. Summary of syntheses of different transition and main group metal oxides from their salts by the epoxide addition method.

\begin{tabular}{ccc}
\hline $\begin{array}{c}\text { Precursor } \\
\text { Salt }\end{array}$ & $\begin{array}{c}\text { metal } \\
\text { oxide }\end{array}$ & gel ? \\
\hline $\mathrm{Fe}\left(\mathrm{NO}_{3}\right)_{3} \cdot 9 \mathrm{H}_{2} \mathrm{O}$ & $\mathrm{Fe}_{2} \mathrm{O}_{3}$ & yes \\
$\mathrm{Al}\left(\mathrm{NO}_{3}\right)_{3} \cdot 9 \mathrm{H}_{2} \mathrm{O}$ & $\mathrm{Al}_{2} \mathrm{O}_{3}$ & yes \\
$\mathrm{In}\left(\mathrm{NO}_{3}\right)_{3} \cdot 5 \mathrm{H}_{2} \mathrm{O}$ & $\mathrm{In}_{2} \mathrm{O}_{3}$ & yes \\
$\mathrm{Ga}\left(\mathrm{NO}_{3}\right)_{3} \cdot \times \mathrm{H}_{2} \mathrm{O}$ & $\mathrm{Ga}_{2} \mathrm{O}_{3}$ & yes \\
$\mathrm{SnCl}_{4} \cdot 5 \mathrm{H}_{2} \mathrm{O}$ & $\mathrm{SnO}_{2}$ & yes \\
$\mathrm{HfCl}_{4}$ & $\mathrm{HfO}_{2}$ & yes \\
$\mathrm{ZrCl}_{4}$ & $\mathrm{ZrO}_{2}$ & yes \\
$\mathrm{NbCl}_{5}$ & $\mathrm{Nb}_{2} \mathrm{O}_{5}$ & yes \\
$\mathrm{TaCl}_{5}$ & $\mathrm{Ta}_{2} \mathrm{O}_{5}$ & yes \\
$\mathrm{WCl}_{6}$ & $\mathrm{WO}_{3}$ & yes \\
& & \\
\hline
\end{tabular}

